\title{
Computed tomographic assessment of lung weights in trauma patients with early posttraumatic lung dysfunction
}

\author{
Andreas W Reske ${ }^{1 * \dagger}$, Alexander P Reske ${ }^{2 \dagger}$, Till Heine ${ }^{3}$, Peter M Spieth², Anna Rau', Matthias Seiwerts ${ }^{4}$, \\ Harald Busse ${ }^{4}$, Udo Gottschaldt ${ }^{1}$, Dierk Schreiter ${ }^{5}$, Silvia Born ${ }^{6}$, Marcelo Gama de Abreu ${ }^{2}$, Christoph Josten ${ }^{3}$, \\ Hermann Wrigge ${ }^{1}$, Marcelo BP Amato ${ }^{7}$
}

\begin{abstract}
Introduction: Quantitative computed tomography (qCT)-based assessment of total lung weight ( $\mathrm{M}_{\text {lung }}$ ) has the potential to differentiate atelectasis from consolidation and could thus provide valuable information for managing trauma patients fulfilling commonly used criteria for acute lung injury (ALI). We hypothesized that qCT would identify atelectasis as a frequent mimic of early posttraumatic ALI.

Methods: In this prospective observational study, $\mathrm{M}_{\text {lung }}$ was calculated by qCT in 78 mechanically ventilated trauma patients fulfilling the ALI criteria at admission. A reference interval for $M_{\text {lung }}$ was derived from 74 trauma patients with morphologically and functionally normal lungs (reference). Results are given as medians with interquartile ranges.

Results: The ratio of arterial partial pressure of oxygen to the fraction of inspired oxygen was 560 (506 to 616) $\mathrm{mmHg}$ in reference patients and 169 (95 to 240) $\mathrm{mmHg}$ in ALI patients. The median reference Mlung value was 885 (771 to 973) $\mathrm{g}$, and the reference interval for $\mathrm{M}_{\text {lung }}$ was 584 to $1164 \mathrm{~g}$, which matched that of previous reports. Despite the significantly greater median $M_{\text {lung }}$ value $(1088(862$ to 1,342$) \mathrm{g})$ in the ALI group, 46 (59\%) ALI patients had $M_{\text {lung }}$ values within the reference interval and thus most likely had atelectasis. In only 17 patients (22\%), $M_{\text {lung }}$ was increased to the range previously reported for ALI patients and compatible with lung consolidation. Statistically significant differences between atelectasis and consolidation patients were found for age, Lung Injury Score, Glasgow Coma Scale score, total lung volume, mass of the nonaerated lung compartment, ventilator-free days and intensive care unit-free days.

Conclusions: Atelectasis is a frequent cause of early posttraumatic lung dysfunction. Differentiation between atelectasis and consolidation from other causes of lung damage by using qCT may help to identify patients who could benefit from management strategies such as damage control surgery and lung-protective mechanical ventilation that focus on the prevention of pulmonary complications.
\end{abstract}

\section{Introduction}

Trauma patients may be affected by several conditions predisposing them to acute lung injury (ALI) and frequently fulfill all criteria for ALI proposed by the American-European Consensus Conference on Acute Respiratory Distress Syndrome (AECC) [1]. However,

\footnotetext{
* Correspondence: andreas.reske@medizin.uni-leipzig.de

† Contributed equally

'Department of Anesthesiology and Intensive Care Medicine, University

Hospital Leipzig, Liebigstrasse 20, D-04103 Leipzig, Germany

Full list of author information is available at the end of the article
}

concerns have been raised that these ALI criteria (acute onset, presence of a typical risk factor, arterial partial pressure of oxygen to fraction of inspired oxygen ratio $\left(\mathrm{PaO}_{2} / \mathrm{FiO}_{2}\right)$ less than $300 \mathrm{mmHg}$, absence of heart failure and bilateral infiltrates visualized on chest X-rays) capture a heterogeneous group of patients and may be nonspecific, particularly in trauma patients [2-4]. The appropriateness of ventilatory management of trauma patients based solely on these criteria has also been questioned $[4,5]$.

\section{C) BiolMed Central}


Computed tomography (CT) has a higher sensitivity than radiographs for detecting lung parenchymal changes [6,7]. Nevertheless, the visual confirmation of bilateral pulmonary infiltrates by CT instead of chest Xrays is not supported by the current ALI definition and carries the risk of detecting pulmonary opacifications with limited clinical relevance [1,6]. Despite this limitation, quantitative CT (qCT) analysis enables the unique noninvasive assessment of total lung weight $\left(\mathrm{M}_{\text {lung }}\right)$ and can be used to distinguish different causes of early posttraumatic pulmonary opacification and thus different populations of ALI patients [2,8-14].

If a patient has pulmonary opacifications on $\mathrm{qCT}$ but has a normal $\mathrm{M}_{\text {lung, }}$, atelectasis due to hypoventilation, the use of anesthetics and high inspiratory oxygen concentrations would be the most likely explanation for impaired oxygenation [15]. If a significantly increased $\mathrm{M}_{\text {lung }}$ suggests consolidation from a more significant lung injury (for example, hemorrhage, contusion or edema from capillary leakage) [10-13], a focus on the prevention of secondary lung injury, such as by performing damage control surgery and implementing lung-protective mechanical ventilation, would appear appropriate [3,4,16-19]. Atelectasis mimicking ALI instead may warrant more aggressive ventilatory management and early definitive surgical management $[4,5,20-24]$.

In this study, we aimed to use qCT to (1) establish a reference interval for $\mathrm{M}_{\text {lung }}$ of mechanically ventilated trauma patients with morphologically and functionally normal lungs and (2) study $\mathrm{M}_{\text {lung }}$ in trauma patients who fulfilled the ALI criteria. We hypothesized that $\mathrm{qCT}$ would identify atelectasis as a frequent mimic of early posttraumatic ALI. In the future, this information could aid in managing patients with early posttraumatic lung dysfunction.

\section{Materials and methods}

Data for this prospective observational study were collected during routine clinical management at the University Hospital Leipzig. The study was approved by the ethics committee of the University of Leipzig (approval numbers 202/2003 and 311/2007). The need for informed consent was waived because no interventions or additional patient manipulations were required.

Our study consisted of two parts (Figure 1). First, we analyzed the $\mathrm{M}_{\text {lung }}$ of trauma patients with normal lungs to establish a reference interval (reference group). Second, $M_{\text {lung }}$ values were assessed in patients with early posttraumatic ALI. A small subset of qCT data used in the present study were analyzed in a previous noninterventional study [25].

\section{Reference group}

Trauma patients with morphologically and functionally normal lungs who underwent emergency CT were divided into spontaneously breathing (reference spontaneous) and mechanically ventilated (reference ventilated) patients (Figure 1 and Table 1). Patients with pneumothorax, pleural fluid or opacifications other than small, localized dorsal atelectasis were not included. The decision whether a lung was normal was based on the consensus of one radiologist and two intensivists. If data were available, the $\mathrm{PaO}_{2} / \mathrm{FiO}_{2}$ ratio had to be greater than $400 \mathrm{mmHg}$.

\section{ALI group}

Trauma patients were eligible for the ALI group if they had undergone CT within 24 hours posttrauma, fulfilled the clinical criteria for ALI (that is, acute onset, typical trigger, absence of heart failure and $\mathrm{PaO}_{2} / \mathrm{FiO}_{2}$ ratio below $300 \mathrm{mmHg}$ ) at admission and CT showed bilateral pulmonary opacifications (Figure 1) [1].

Physiological and demographic data were obtained from the patient data management system into which these data had been prospectively and automatically entered. The ventilator-free days and the intensive care unit (ICU)-free days were calculated as the number of days without mechanical ventilation or ICU treatment, respectively, within a period of 28 days [26]. The Lung Injury Score (LIS), the Injury Severity Score (ISS), the Abbreviated Injury Scale of the Thorax (AIS-T) and the Thoracic Trauma Severity Score (TTSS) were calculated at the time of admission [27-29]. The Glasgow Coma Scale (GCS) score at the trauma scene and the amount of intravenous fluids administered prior to CT were calculated on the basis of the ambulance report form.

Pressure-controlled mechanical ventilation (reference ventilated and ALI) during primary resuscitation and $\mathrm{CT}$ was standardized and included the following ventilator settings (Oxylog 3000; Dräger, Lübeck, Germany): target tidal volume of $6 \mathrm{ml} / \mathrm{kg}$ estimated body weight (estimated weight in kilograms equals height in centimeters minus 100), respiratory rate of 20 breaths $\mathrm{min}^{-1}$ and positive end-expiratory pressure of $10 \mathrm{cmH}_{2} \mathrm{O}$ $[21,30]$.

\section{CT scanning}

Each CT scan was requested by the treating physicians as routine diagnostic procedure in emergency trauma patients [21,31]. Depending on availability, two multislice CT scanners were used, either a Somatom Volume Zoom (120-kV tube voltage, $165-\mathrm{mA}$ tube current, $4 \times$ 2.5-mm collimation; Siemens, Erlangen, Germany) or a Philips MX8000 IDT 16 (120-kV tube voltage, 170-mA tube current, $16 \times 1.5-\mathrm{mm}$ collimation; Philips Medical Systems, Hamburg, Germany). As part of routine clinical imaging, contiguous images were reconstructed with either $10-\mathrm{mm}$ slice thickness and the enhancing filter "B60f" on the Siemens scanner or 5-mm thickness and 


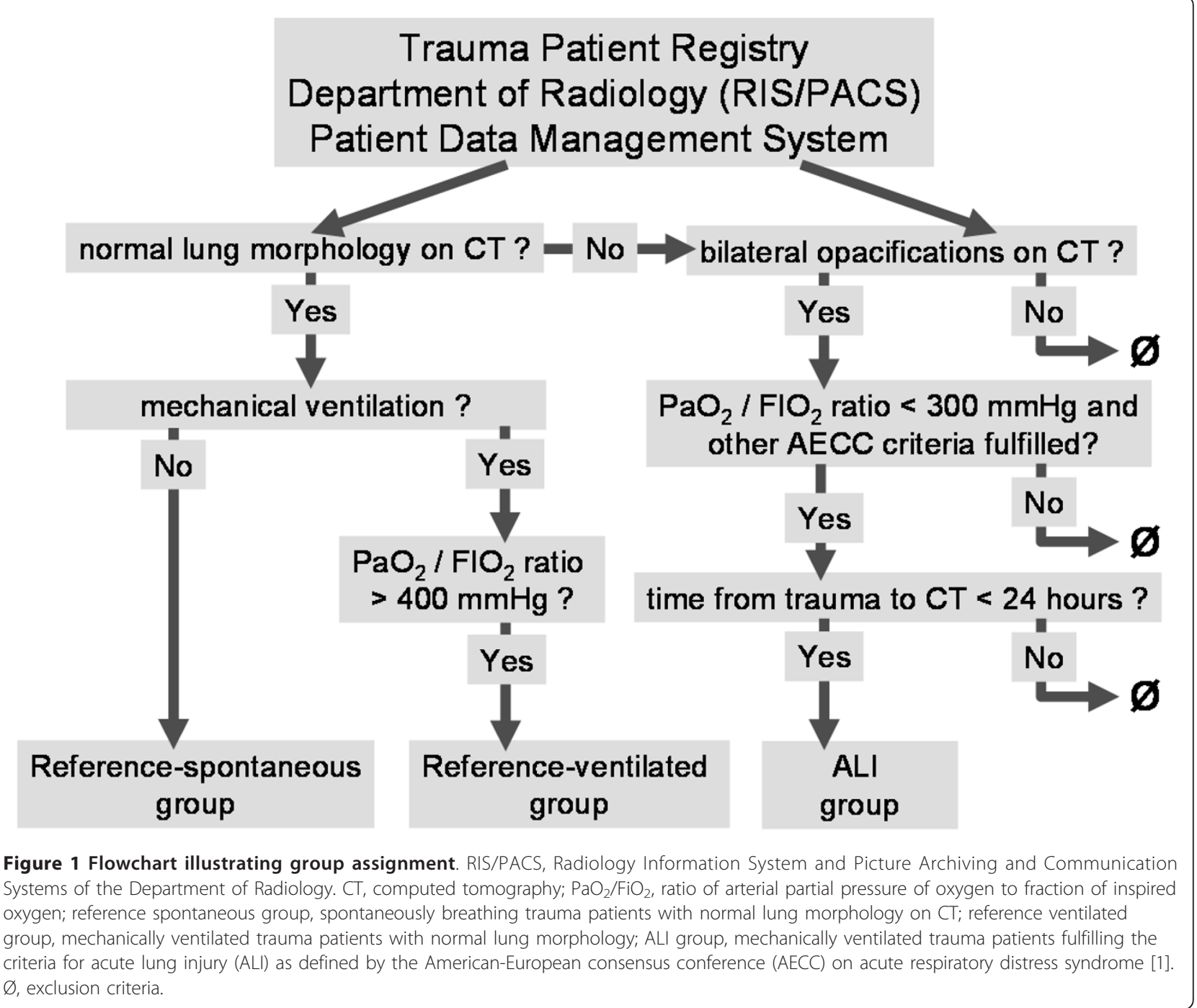

the standard filter " $\mathrm{B}$ " on the Philips scanner. Intravenous with contrast material (120 ml of iopamidol 300; Schering, Berlin, Germany) was used as part of the clinical protocol in all patients. Because of the observational study design, the degree of inspiration during CT could not be controlled: Reference spontaneous patients were asked to hold their breath after inspiration (without checking for compliance) during CT. Reference ventilated and ALI patients were scanned during uninterrupted mechanical ventilation, which is current clinical practice in our institution. Calibration of the CT scanners was performed using air and the manufacturer's standard phantom.

\section{Quantitative CT analysis}

The lung parenchyma was segmented manually in CT images covering the entire lungs (Osiris software; University Hospital Geneva, Geneva, Switzerland) [25].
Window levels and widths appropriate for the lung parenchyma $(-500 / 1,500 \mathrm{HU})$ or the mediastinum $(50 / 250$ HU) were used. Major hilar vessels and bronchi, pneumothoraces, pleural fluids and gross motion artefacts were manually excluded. Only in aerated lung regions did we use a threshold ( $-350 \mathrm{HU})$-based segmentation technique in an attempt to guide and standardize the manual exclusion of partial volume effects close to the thoracic wall, mediastinum, heart or diaphragm. To do so, window level and width were set to $(-350 / 0 \mathrm{HU})$, and the segmentation line was drawn at the black-white interface [32-34]. Opacified lung regions were segmented manually using anatomical landmarks.

The total lung volume $\left(V_{\text {lung }}\right)$, the total lung mass $\left(\mathrm{M}_{\text {lung }}\right)$ and the masses of differently aerated lung compartments were calculated voxel-by-voxel using customized software as previously described [9,10,12,25,35]. $\mathrm{M}_{\text {lung }}$ and $\mathrm{V}_{\text {lung }}$ values were calculated on the basis of 
Table 1 Demographic data ${ }^{a}$

\begin{tabular}{|c|c|c|c|}
\hline Patient demographics & ALI & Reference ventilated & Reference spontaneous \\
\hline Number of patients & 78 & 43 & 31 \\
\hline Median age ${ }^{\text {ns }}$ & 42 (23 to 51$)$ & 27 (21 to 45$)$ & 32 (22 to 44$)$ \\
\hline Sex (male/female) ${ }^{b}$ & $61 / 17$ & $37 / 6$ & $19 / 12$ \\
\hline Median height ${ }^{b}, \mathrm{~cm}$ & $176(173$ to 180$)$ & 175 (170 to 183$)$ & $174(168$ to 183$)$ \\
\hline Median weight ${ }^{\mathrm{b}}, \mathrm{kg}$ & 80 (74 to 90$)$ & 75 (70 to 82) & 73 (59 to 85$)$ \\
\hline Median Body Mass Index ${ }^{\mathrm{b}}, \mathrm{kg} \mathrm{m}^{-2}$ & 26 (23 to 28$)$ & 24 (23 to 26$)$ & 23 (21 to 24$)$ \\
\hline Median $\mathrm{PaO}_{2} / \mathrm{FiO}_{2}, \mathrm{mmHg}$ & 169 (95 to 240$)$ & $560(506 \text { to } 616)^{d}$ & n.a. \\
\hline Median Lung Injury Score & 2.3 (2.0 to 3.0$)$ & n.a. & n.a. \\
\hline Median Injury Severity Score ${ }^{c}$ & 36 (29 to 48$)$ & $20(12 \text { to } 26)^{d}$ & $12(6 \text { to } 16)^{\mathrm{d}, \mathrm{e}}$ \\
\hline Median AIS-T & 4 (4 to 4$)$ & n.a. & n.a. \\
\hline Median Thoracic Trauma Severity Score ${ }^{b}$ & 11 (9 to 14 ) & n.a. & n.a. \\
\hline Median Glasgow Coma Scale score ${ }^{c}$ & $11(4$ to 15$)$ & $11(7$ to 15$)$ & $15(15 \text { to } 15)^{\mathrm{d}, \mathrm{e}}$ \\
\hline Median volume of intravenous fluids ${ }^{c}, \mathrm{ml}$ & $2,000(1,125$ to 3,000$)$ & $1,000(500 \text { to } 1,500)^{d}$ & $1,000(500 \text { to } 1,000)^{d}$ \\
\hline Median time to $C T^{\mathrm{ns}}$, $\min$ & 122 (90 to 207) & 105 (79 to 129$)$ & $100(81$ to 136$)$ \\
\hline Median ventilator-free days ${ }^{b}$ & 17 (4 to 23$)$ & 27 (19 to 27$)$ & n.a. \\
\hline Median ICU-free days ${ }^{\mathrm{b}}$ & $7(0$ to 17$)$ & $22(10$ to 26$)$ & n.a. \\
\hline
\end{tabular}

${ }^{a}$ All values are given as medians with interquartile ranges. ALI, patients with acute lung injury at admission; reference ventilated, mechanically ventilated patients with normal lungs; reference spontaneous, spontaneously breathing patients with normal lungs; Body Mass Index, weight in kilograms divided by the square of the height in meters; $\mathrm{PaO}_{2} / \mathrm{FiO}_{2}$, ratio of arterial partial pressure of oxygen to fraction of inspired oxygen; AIS-T, Abbreviated Injury Scale of the Thorax; time to $\mathrm{CT}$, interval between trauma and computed tomography (CT); ventilator-free days, number of days without mechanical ventilation within a period of 28 days; ICU, intensive care unit; ICU-free days, number of days without ICU treatment within a period of 28 days; n.a., not applicable; ${ }^{\text {ns }}$, not significant. Positive endexpiratory pressure (PEEP) was $10 \mathrm{cmH}_{2} \mathrm{O}$ in all mechanically ventilated patients except for five; in three patients, $\mathrm{PEEP}>10 \mathrm{~cm} \mathrm{H}_{2} \mathrm{O}$ was already applied before admission and two patients were spontaneously breathing during CT. ${ }^{b}$ No statistical test performed. ${ }^{c} P<0.001$ for the Kruskal-Wallis test over all groups. ${ }^{d} P<$ 0.001 versus ALI. ${ }^{e} P<0.05$ versus reference ventilated group.

all lung voxels within the $-1,000$ to $+100 \mathrm{HU}$ range. The following $\mathrm{HU}$ ranges were used to separate differently aerated lung compartments: nonaerated, -100 to +100 $\mathrm{HU}$; poorly aerated, -101 to $-500 \mathrm{HU}$; normally aerated, -501 to $-900 \mathrm{HU}$; and hyperaerated, -901 to $-1,000 \mathrm{HU}$. The masses of differently aerated lung compartments were calculated as percentages of $\mathrm{M}_{\text {lung. }}$. Although it was calculated, we omitted between-group comparison of the hyperaerated compartment because two different $\mathrm{CT}$ scanners and image reconstruction protocols were used, and such comparison was not required for the present study [30].

The validity of our analytical method was reviewed in 27 patients by placing a water-filled plastic bottle next to the thorax. We then selected an arbitrary region of interest (ROI) within this bottle in the CT image and compared the weight resulting from our voxel-by-voxel analysis method with that obtained by simply multiplying the volume of interest (ROI area $\times$ slice thickness) by the volumetric mass density of water (approximately $997.77 \mathrm{~kg} / \mathrm{m}^{3}$ at $\left.22^{\circ} \mathrm{C}\right)$.

\section{Statistical analysis}

Data are given as medians with interquartile ranges unless specified otherwise. According to Clinical and Laboratory Standards Institute guideline C28-A3 [36], the $95 \%$ reference interval of $M_{\text {lung }}$ was calculated using the robust method because the number of reference subjects was smaller than 120 [36,37]. Results were compared between subgroups using the Mann-Whitney $U$ test or the Kruskal-Wallis test. Confidence intervals (95\% CI) for normal $M_{\text {lung }}$ reported in previous studies were calculated [38]. Analysis of variance (ANOVA) was used to compare the $M_{\text {lung }}$ values from these previous studies with our reference patients (Shapiro-Wilk test indicated normal distribution). Linear regression analysis was used to calculate coefficients and 95\% CIs for the correlation of body height and weight with $\mathrm{M}_{\text {lung. }}$. The effect of adjusting for sex, age and group regarding the relationship between $M_{\text {lung }}$ and body height was tested by entering these variables into the regression model. It was defined a priori that only variables explaining $\geq 5 \%$ of the variance in $\mathrm{M}_{\text {lung }}$ values would be kept in the final model. Bland-Altman plots were used to compare the ROI weights used for validation of our voxel-byvoxel analytical method [39]. All tests were two-sided. Statistical significance was assumed if $P<0.05$. Statistical analyses were performed using SPSS 12.0 software (SPSS, Inc., Chicago, IL, USA) and MedCalc software (MedCalc Software, Mariakerke, Belgium).

\section{Results}

\section{Reference patients}

We analyzed 74 trauma patients with morphologically and functionally normal lungs. Reference ventilated patients were more frequently male, more severely 
injured and received more intravenous fluids than reference spontaneous patients. One reference ventilated patient $(2 \%)$ died as a result of severe head injury. Demographic data are given in Table 1.

Results from qCT are given in Table 2. Supporting their classification as normal, all reference patients had negligible amounts of nonaerated lung (Table 2). The median $\mathrm{M}_{\text {lung }}$ of all reference patients was 885 (771 to 973) $\mathrm{g}$, and the mean $\mathrm{M}_{\text {lung }}$ of all reference patients was 871 (95\% CI, 838 to 905$)$ g. The 95\% reference interval for $\mathrm{M}_{\text {lung }}$ was 584 to $1,164 \mathrm{~g}$. No significant differences $(P=0.55$; ANOVA $)$ were found between mean $M_{\text {lung }}$ values of reference ventilated, reference spontaneous or mean normal $\mathrm{M}_{\text {lung }}$ reported by Gattinoni et al. [10] (850 (95\% CI, 785 to 915) g), Puybasset et al. [11] (943 (95\% CI, 857 to 1,029) g) and Whimster et al. [40] (850 (95\% CI, 818 to 881$) \mathrm{g}$ ).

For reference patients, $\mathrm{M}_{\text {lung }}$ correlated moderately with body height $\left(R^{2}=0.35, P<0.0001\right)$, but not reliably with actual body weight $\left(R^{2}=0.14\right)$. The equation for the regression of $\mathrm{M}_{\text {lung }}$ (in grams) on body height (in centimeters) for all reference patients had the following parameters: coefficient (height) $=9.3(95 \% \mathrm{CI}, 6.4$ to $12.3)$ and $y$-intercept $=-768(95 \% \mathrm{CI},-1291$ to -246$)$. Adjustment for sex by including a dummy-coded sex variable $($ male $=0)$ significantly improved the model for regression of $\mathrm{M}_{\text {lung }}$ on body height $\left(\Delta R^{2}=0.05, P=\right.$ 0.02 for the $R^{2}$ change). The parameters of the sexadjusted regression equation were coefficient (height) $=$ 7.2 (95\% CI, 3.8 to 10.6), coefficient (sex) $=-88.6(95 \%$ CI, -160.7 to -16.5$)$ and $y$-intercept $=-365(95 \% \mathrm{CI}$, -973 to 244). Adjusting for age or group (reference spontaneous versus reference ventilated) did not improve the model ( $P=0.65$ and $P=0.14$, respectively).

\section{ALI patients}

Seventy-eight patients fulfilled the AECC criteria for ALI at admission. All patients were severely injured, and only one patient (ISS $=12$ ) had an ISS below 16 points. Demographic data are given in Table 1, and the results of qCT are given in Table 2.

Fifteen ALI patients (19\%) died as a result of nonpulmonary complications, nine patients died of severe head injury, five died of uncontrollable hemorrhage and one died of late sepsis and multiorgan failure. Patients who died did not have greater $M_{\text {lung }}$ than survivors $(P=$ 0.75 ). Patients with severe head injury (GCS score $<8, n$ = 30) [41] had significantly greater $M_{\text {lung }}(1,274$ (962 to $1,634) \mathrm{g})$ than patients with GCS score $\geq 8(n=48,981$ (802 to 1,161$)$ g; $P<0.001)$.

Although the median $\mathrm{M}_{\text {lung }}(1,088$ (862 to 1,342$) \mathrm{g}$ ) of our ALI patients was significantly greater than that of our reference patients $(P<0.0001)$, it was lower than the mean values reported for other ALI patients, for example by Patroniti et al. $(1,513(95 \%$ CI 1,426 to 1,600$) \mathrm{g})$ and by Gattinoni et al. $(1,500$ (95\% CI 1,380 to 1,620$) \mathrm{g})[10,12,42]$.

No reliable correlation was found between $M_{\text {lung }}$ and scores for trauma severity (ISS, AIS-T, TTSS, LIS and GCS), the volume of intravenous fluids, the $\mathrm{PaO}_{2} / \mathrm{FiO}_{2}$ ratio or the time between trauma and CT (all $R^{2} \leq 0.16$ ).

Forty-six (59\%) ALI patients had $M_{\text {lung }}$ below the upper limit of the reference interval (that is, 1,164 g) and were thus allocated to an atelectasis subgroup (Figure 2, Table 3). We also defined a consolidation subgroup using the lower limit of the $95 \% \mathrm{CI}$ of the mean $\mathrm{M}_{\text {lung }}$ (i.e. $1380 \mathrm{~g}$ ) reported for ALI patients by Gattinoni et al. [10]. Statistically significant differences between atelectasis and consolidation patients were found for the parameters age, LIS, GCS, $\mathrm{V}_{\text {lung, }}$, mass of

Table 2 Lung volumes and weights quantified by $\mathrm{CT}^{\mathrm{a}}$

\begin{tabular}{|c|c|c|c|}
\hline Parameter & ALI & Reference ventilated & Reference spontaneous \\
\hline$\overline{M e d i a n} \mathrm{~V}_{\text {lung }}{ }^{\mathrm{b}}, \mathrm{ml}$ & $3,208(2,574$ to 4,289$)$ & $4,228(3,701$ to 4,621$)$ & $3,195(2,670$ to 4,918$)$ \\
\hline Median $V_{\text {lung }}$ in women ${ }^{b}, \mathrm{ml}$ & $2,865$ (2,413 to 3,293$)$ & $3,498(2,957$ to 3,948$)$ & $2779(2,526$ to 3,878$)$ \\
\hline Median $V_{\text {lung }}$ in $\mathrm{men}^{\mathrm{b}}, \mathrm{ml}$ & $3,304(2,562$ to 4,513$)$ & $4,426(3,801$ to 4,760$)$ & $3363(2,979$ to 6,121$)$ \\
\hline Median Mlung ${ }^{c}, g$ & $1,088$ (862 to 1,342$)$ & $893\left(\right.$ (785 to 968) $^{d}$ & 884 (724 to 986) d,e \\
\hline Median $M_{\text {lung }}$ in women, $\mathrm{g}$ & 814 (748 to 1,250$)$ & 738 (664 to 765$)$ & 720 (620 to 824) \\
\hline Median $M_{\text {lung }}$ in men, $\mathrm{g}$ & $1,119$ (913 to 1,358$)$ & 902 (847 to 981) & 928 (864 to 993) \\
\hline Median $M_{\text {hyper }}$, $\%$ & $0(0$ to 3$)$ & 2 (0 to 4$)$ & 0 (0 to 4$)$ \\
\hline Median $M_{\text {normal }}$, $\%$ & 55 (39 to 68 ) & 88 (85 to 91$)$ & 85 (79 to 88$)$ \\
\hline Median $M_{\text {poor }}{ }^{b}, \%$ & 17 (14 to 23$)$ & $6(6$ to 10$)$ & $9(7$ to 17$)$ \\
\hline Median $M_{\text {non }}{ }^{b}, \%$ & 20 (11 to 34$)$ & 1 (1 to 2$)$ & 1 (1 to 2$)$ \\
\hline
\end{tabular}

${ }^{a}$ All values are given as medians with interquartile ranges. ALI, patients with acute lung injury already at admission; reference ventilated, mechanically ventilated patients with normal lungs; reference spontaneous, spontaneously breathing patients with normal lungs; $V_{\text {lung, }}$ total lung volume; $M_{\text {lung, }}$ total lung mass; $M_{\text {hyper, }}$ mass of hyperaerated lung compartment; $M_{\text {normal, }}$ mass of normally aerated lung compartment; $M_{\text {poor, }}$ mass of poorly aerated lung compartment; $M_{\text {non }}$, mass of nonaerated lung compartment. The weights of differently aerated lung compartments were calculated as percentages of $M_{\text {lung. }}$. $V_{\text {lung }}$ and $M_{\text {lung }}$ values were calculated for each sex separately as well as for all patients in a group to assess sex-specific differences. ${ }^{b}$ Because the degree of inspiration was not controlled during computed tomography, between-group comparison of $V_{\text {lung }}$ and differently aerated lung compartments was omitted. ${ }^{c} p<0.001$ for the Kruskal-Wallis test

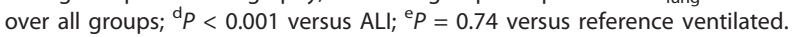




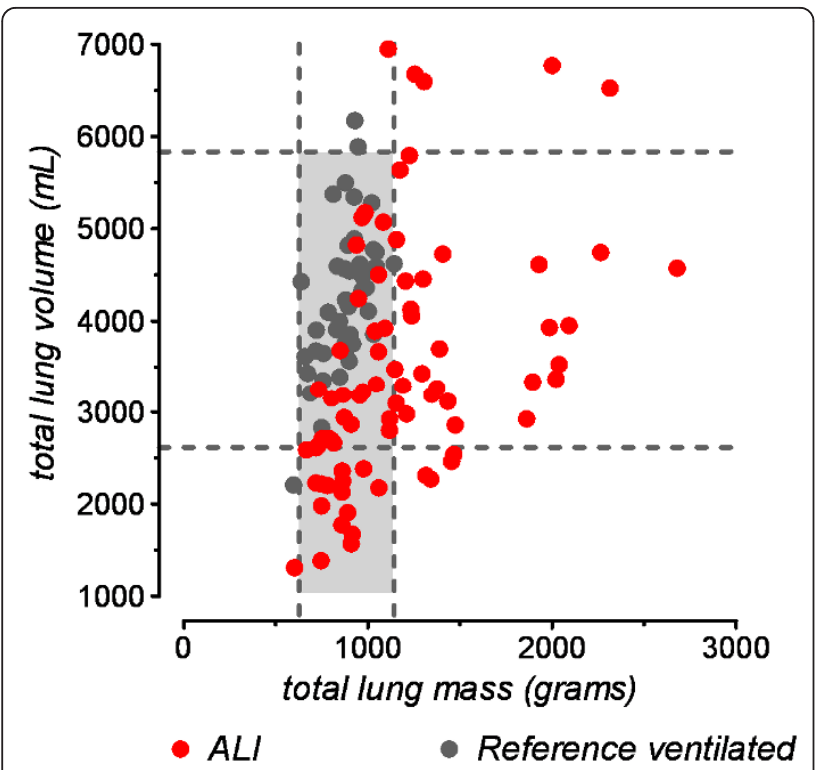

Figure 2 Comparison of lung weights. Lung weights of 78 patients with acute lung injury (ALI) upon admission (red circles) in comparison to the values of 43 mechanically ventilated trauma patients with morphologically and functionally normal lungs (reference ventilated, gray circles). Dashed lines mark the 95\% reference intervals for total lung mass and total lung volume, respectively, calculated from reference ventilated patients. Because reference ventilated patients were ventilated with the same positive end-expiratory pressure $\left(10 \mathrm{cmH}_{2} \mathrm{O}\right)$ and also underwent computed tomography during uninterrupted mechanical ventilation, only these reference ventilated patients were used for the graphical comparison with ALI patients in this graph. ALI patients whose data points fall within the gray box did not have an increased lung weight

the nonaerated lung compartment and, interestingly, ventilator-free days and ICU-free days (Table 3).

\section{Validation of the mass estimation technique}

The mean ( \pm standard deviation) weight of the test-ROI obtained by geometrical calculation was $13.0 \pm 5.4 \mathrm{~g}$. The values from our voxel-by-voxel method were slightly smaller. The mean difference (bias) between both methods was $-2.4 \%$ and the limits of agreement were $-4.6 \%$ and $0.2 \%$ of the mean weight of the testROI.

\section{Discussion}

We found that atelectasis was the most likely cause of lung dysfunction in more than half of patients who fulfilled the clinical criteria for ALI and showed lung opacifications on admission CT early after trauma.

Comparison of $\mathrm{M}_{\text {lung }}$ values derived from $\mathrm{qCT}$ with a reference interval for normal $\mathrm{M}_{\text {lung }}$ could help to assess the etiology of ALI and improve the definition of different populations of ALI patients $[2,8,10-14,42]$. A group of mechanically ventilated, volume-loaded trauma patients with morphologically and functionally normal lungs offered us the opportunity to confirm the normal range of $\mathrm{M}_{\text {lung }}$ obtained in previous analyses of diagnostic CT in healthy, spontaneously breathing volunteers $[10,11]$. The $M_{\text {lung }}$ values measured in our reference groups are in good agreement with the $\mathrm{M}_{\text {lung }}$ values from these previous $\mathrm{qCT}$ analyses and $\mathrm{M}_{\text {lung }}$ of normal lungs at autopsy $[10,11,40]$. Thus, our results suggest that moderate positive intrathoracic pressure potentially affecting pulmonary blood and/or lymph flow and moderate intravenous volume loading have limited effect on $\mathrm{M}_{\text {lung. }}$.

Calculation of $\mathrm{M}_{\text {lung }}$ and parameters such as the excess lung tissue or weight by performing $\mathrm{qCT}$ can help to distinguish atelectasis from consolidation due to more significant lung damage [10-13,43]. It could be argued that atelectasis may also be distinguished visually from contusion or edema on the basis of typical topographical distributions. Analysis of qCT, however, can still assess $M_{\text {lung }}$ in the presence of pleural fluid or when atelectasis is obscuring edema or pulmonary contusions $[16,22]$. When lung aeration is impaired without a concomitant increase in $\mathrm{M}_{\text {lung }}$, atelectasis is the most likely explanation $[11,13]$. Accordingly, atelectasis was the most plausible cause of lung dysfunction in $59 \%$ of our ALI patients (Table 3). Interestingly, atelectasis patients also had significantly lower $\mathrm{V}_{\text {lung }}$ values than consolidation patients (Table 3). Although $V_{\text {lung }}$ was not controlled in our study, the latter observation is compatible with the concept of atelectasis: $V_{\text {lung }}$ is reduced by collapse, while consolidation of the lung does not necessarily decrease $V_{\text {lung }}$ [44]. The identification of trauma patients in whom atelectasis mimics ALI could be helpful in decision making and individualization of care (that is, early definitive stabilization rather than damage control surgery). Atelectasis may persist into the posttraumatic period, promote bacterial growth and nosocomial pneumonia and affect patient outcome $[3,23,45-50]$. Therefore, more aggressive ventilatory management, early definitive surgical treatment and timely weaning from mechanical ventilation could shorten the ICU treatment and reduce the incidence of infections in patients with atelectasis $[4,20-24,49]$.

Thirty-two ALI patients (41\%) had increased $\mathrm{M}_{\text {lung. }}$. In only 17 patients (22\%) was $\mathrm{M}_{\text {lung }}$ increased to the range previously reported for ALI patients, suggesting consolidation from more significant lung injury due to contusion, hemorrhage, aspiration or edema resulting from pulmonary and/or systemic inflammation with capillary leakage [10-13]. Although fluid overload may also play a role [3], we did not find significantly higher infusion volumes in consolidation patients, and all five patients who received more than four liters of infusions had $M_{\text {lung }}$ values within the reference interval (Table 3). The 
Table 3 Patient subgroups defined by different ranges of lung weights ${ }^{\mathrm{a}}$

\begin{tabular}{|c|c|c|c|}
\hline Patient subgroups & Atelectasis ( $\leq$ reference range) & Above reference range & Consolidation \\
\hline Definition & $M_{\text {lung }} \leq 1,164 \mathrm{~g}$ & $M_{\text {lung }}>1,164 \mathrm{~g}$ & $M_{\text {lung }}>1,380 \mathrm{~g}$ \\
\hline Number of patients ${ }^{b}$ & $46(59 \%)$ & $32(41 \%)$ & $17(22 \%)$ \\
\hline Median age ${ }^{c}, y r$ & 45 (32 to 53 ) & 28 (17 to 46$)$ & 21 (17 to 48$)$ \\
\hline Median $\mathrm{PaO}_{2} / \mathrm{FiO}_{2}{ }^{\mathrm{ns}}, \mathrm{mmHg}$ & 184 (128 to 252$)$ & 136 (78 to 238$)$ & 132 (68 to 230$)$ \\
\hline Median Lung Injury Score ${ }^{e}$ & 2.3 (1.6 to 2.6$)$ & 2.7 (2.3 to 3.3$)$ & $3.0(2.3$ to 3.3$)$ \\
\hline Median Injury Severity Score ${ }^{\text {ns }}$ & 34 (29 to 45$)$ & 41 (28 to 50$)$ & $36(25$ to 50$)$ \\
\hline Median AIS-T score ${ }^{b}$ & 4 (4 to 4$)$ & $4(4$ to 4$)$ & $4(4$ to 4$)$ \\
\hline Median Thoracic Trauma Severity Score ${ }^{\text {ns }}$ & $11(8$ to 14$)$ & $12(9$ to 15$)$ & $12(11$ to 15$)$ \\
\hline Median Glasgow Coma Scale score & $14(10$ to 15$)$ & 6 (3 to 12$)$ & 7 (3 to 15$)$ \\
\hline Median volume of intravenous fluids ${ }^{\mathrm{ns}}, \mathrm{ml}$ & $2,000(1,000$ to 3,000$)$ & $2,000(1,500$ to 2,875$)$ & $2,500(1,500$ to 3,000$)$ \\
\hline Median time to $C T^{\mathrm{ns}}$, min & 135 (90 to 220$)$ & $112(90$ to 177$)$ & 131 (103 to 227) \\
\hline Median ventilator-free days ${ }^{d}$ & 19 (10 to 25$)$ & 15 (0 to 19) & $15(0$ to 19$)$ \\
\hline Median ICU-free days ${ }^{c}$ & 14 (2 to 22$)$ & $1(0$ to 13$)$ & $5(0$ to 14$)$ \\
\hline Median $V_{\text {lung }}{ }^{e}, \mathrm{ml}$ & $2,832(2,226$ to 3,669$)$ & $3,812(3,134$ to 4,696$)$ & $3,696(3,019$ to 4,668$)$ \\
\hline Median $M_{\text {lung }}{ }^{b}, g$ & 899 (787 to 1,048$)$ & $1,398(1,265$ to 1,972$)$ & $1,930(1,461$ to 2,065$)$ \\
\hline Median $M_{\text {non }}{ }^{e}, \%$ & 16 (10 to 25$)$ & 34 (18 to 52$)$ & 40 (33 to 57$)$ \\
\hline
\end{tabular}

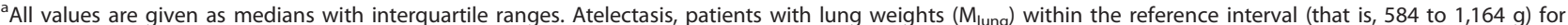
normal $M_{\text {lungi }}$ above reference, patients with $M_{\text {lung }}$ values exceeding the upper limit of the reference interval (that is, 1,164 g); consolidation, patients with $M_{\text {lung }}$ values exceeding the lower limit of the $95 \%$ confidence interval of the mean $\mathrm{M}_{\text {lung }}$ values reported for patients with acute lung injury (that is, $1,380 \mathrm{~g}$ [10]); $\mathrm{PaO}_{2} / \mathrm{FiO}_{2}$, ratio of arterial partial pressure of oxygen to fraction of inspired oxygen; AIS-T, Abbreviated Injury Scale of the Thorax; time to CT, interval between trauma and computed tomography (CT); ventilator-free days, number of days without mechanical ventilation within a period of 28 days; ICU, intensive care unit; ICU-free days, number of days without ICU treatment within a period of 28 days; $V_{\text {lung, }}$ total lung volume; $M_{\text {lung, }}$ total lung mass; $M_{\text {non, }}$ percentage mass of nonaerated lung compartment (percentage of $\mathrm{M}_{\text {lung }}$ value); ${ }^{\text {ns }}$, not significant. ${ }^{b}$ No statistical test performed. ${ }^{c} p<0.05$, ${ }^{d} P<0.001$ and ${ }^{e} P<0.01$, respectively, for the Kruskal-Wallis test over all groups.

association of severe head injury with increased $\mathrm{M}_{\text {lung }}$ further underlines the fact that multiple factors, such as neurogenic pulmonary edema, may be involved in the development of posttraumatic lung dysfunction [41]. Even if the precise etiology of posttraumatic lung dysfunction remains unclear in some patients, information on preexisting lung damage could help clinicians to judge the individual patient's tolerance for further aggressive shock resuscitation and definitive surgical repair $[20,24]$. It could also guide clinicians in choosing treatment concepts such as lung-protective mechanical ventilation or damage control surgery, which are focused on the prevention of "second hits" to lungs which have already been primed by shock and pulmonary or systemic injuries. Among such "second hits" are surgical trauma, ongoing intraoperative blood loss and transfusion, fat embolism following intramedullary nailing or injurious mechanical ventilation [3,17-20,51].

Parameters such as ISS or $\mathrm{PaO}_{2} / \mathrm{FiO}_{2}$, which have previously been used for the prediction and further characterization of posttraumatic ALI, failed to distinguish atelectasis from consolidation patients $[3,52,53]$. In contrast, age as well as LIS, GCS and qCT results differed statistically significantly between these groups. Interestingly, atelectasis patients spent fewer days on mechanical ventilation and in the ICU than consolidation patients (Table 3 ). However, given the fact that all patients fulfilling the ALI criteria early after trauma have been managed according to the damage control concept in our institution, the latter differences should be considered hypothesis-generating rather than hypothesis-confirming. The variable reliability of clinical parameters and scores for characterizing posttraumatic ALI supports the potential clinical usefulness of $\mathrm{qCT}$, which is the only available in vivo method to directly and reliably quantify $\mathrm{M}_{\text {lung }}$ and the amount of nonaerated lung tissue, which both characterize the severity of lung injury [10-12,52].

Some aspects of our methodology warrant discussion. (1) We studied ALI patients within 24 hours after trauma (Table 1) because it was our aim to study the etiology of early posttraumatic respiratory failure, which may differ significantly from respiratory problems developing later $[3,4,49,54]$. (2) All whole-body CT scans performed in our emergency trauma patients routinely involved the clinically indicated application of contrast material $[21,31]$. A possible effect of contrast material on the normal $\mathrm{M}_{\text {lung }}$ was the reason why we included a reference group and did not refer only to existing data $[10,11,40,55]$. The normal $M_{\text {lung }}$ found in our reference patients matched that in previous reports, which supports the lack of an effect of contrast material on the $\mathrm{qCT}$ assessment of $\mathrm{M}_{\text {lung }}$ in patients with normal lungs [55]. Patients with atelectasis should also remain unaffected by a possible contrast material-associated increase in $\mathrm{M}_{\text {lung. }}$. In contrast, the leakage of contrast material 
into the pulmonary interstitium may artefactually increase $\mathrm{M}_{\text {lung }}$ calculated on the basis of $\mathrm{qCT}$ in patients with an injured alveolar-capillary barrier [55]. However, although desirable from a scientific perspective, contrast material administration appears unavoidable in emergency trauma patients, and a possible artefactual increase in $\mathrm{M}_{\text {lung }}$ must be taken into account. (3) Because varying segmentations result in inconsistent $\mathrm{M}_{\text {lung }}$ values, we used a threshold-based (-350 HU) segmentation technique in addition to manual segmentation to improve the highly subjective manual exclusion of partial volume effects at the boundaries of aerated lung regions. So far, no CT study in ALI patients has included such attempts, and thus this threshold was adopted from other thoracic qCT applications. (4) Because the manual interaction necessary for qCT analysis is time-consuming, it might still be considered unrealistic to introduce qCT-based information into clinical practice. The extrapolation method, which we described recently, offers significant time savings and could aid the clinical implementation of qCT $[14,25]$.

\section{Limitations of our study}

Because chest X-rays were not obtained in addition to CT scans during routine clinical imaging, we could not confirm the presence of infiltrates conventionally on the basis of chest X-rays. Moreover, our results may not be directly transferrable to patients subjected to higher intrathoracic pressures or massive intravenous volume loading. While $\mathrm{M}_{\text {lung }}$ is only minimally affected, parameters characterizing lung aeration and volume depend on the degree of inspiration as well as on differences between CT scanners and image reconstruction protocols. Because CT scanning was performed during ongoing mechanical ventilation, the end-expiratory amount of nonaerated lung might have been underestimated. Different CT scanners and image reconstruction interact with the quantification of hyperaeration. Therefore, we omitted the between-group comparison of the differently aerated lung compartments, which was not the focus of the present study (Table 2) [30].

\section{Conclusions}

$\mathrm{qCT}$ can detect different etiologies of posttraumatic lung dysfunction. Atelectasis was the most likely cause of early posttraumatic lung dysfunction in more than half of our patients. Whether individualized care based on qCT actually offers an option to prevent secondary lung injury, reduce posttraumatic pulmonary complications and improve outcome remains to be studied.

\section{Key messages}

- Diagnosis, management and further study of ALI in trauma patients may be hampered by uncertainties about the fulfillment of the criteria for ALI proposed by the AECC.

- Differentiation between atelectasis and consolidation of the lung by qCT may help to identify patients with different etiologies of posttraumatic lung dysfunction.

- In our study, atelectasis was the most likely cause of early posttraumatic lung dysfunction in more than half of patients, and only $20 \%$ of patients had $\mathrm{M}_{\text {lung }}$ values in the range previously reported for ALI.

- Trauma patients with atelectasis may require shorter periods of mechanical ventilation and treatment in the ICU.

- In the future, information from qCT could aid in managing patients with early posttraumatic lung dysfunction.

\section{Abbreviations}

AECC: American-European Consensus Conference on Acute Respiratory Distress Syndrome; AIS-T: Abbreviated Injury Scale of the Thorax; ALI: acute lung injury; ANOVA: analysis of variance; ARDS: acute respiratory distress syndrome; $95 \% \mathrm{Cl}$ : 95\% confidence interval; $\mathrm{CT}$ : computed tomography; $\mathrm{FiO}_{2}$ fraction of inspired oxygen; GCS: Glasgow Coma Scale; HU: Hounsfield units; ICU: intensive care unit; IQR: interquartile range; ISS: Injury Severity Score; LIS: Lung Injury Score; $\mathrm{M}_{\text {lung: }}$ I lung weight; $\mathrm{PaO}_{2}$ : arterial partial pressure of oxygen; PEEP: positive end-expiratory pressure; qCT: quantitative analysis of computed tomography; TTSS: Thoracic Trauma Severity Score; $V_{\text {lung: lung }}$ volume.

\section{Acknowledgements}

Institutional funding was provided by Leipzig University Hospital.

\section{Author details}

${ }^{1}$ Department of Anesthesiology and Intensive Care Medicine, University Hospital Leipzig, Liebigstrasse 20, D-04103 Leipzig, Germany. ${ }^{2}$ Pulmonary Engineering Group, Department of Anesthesiology and Intensive Care Medicine, University Hospital Carl Gustav Carus, Fetscherstrasse 74, D-01307 Dresden, Germany. ${ }^{3}$ Department of Trauma and Reconstructive Surgery, University Hospital Leipzig, Liebigstrasse 20, D-04103 Leipzig, Germany. ${ }^{4}$ Department of Diagnostic and Interventional Radiology, University Hospital Leipzig, Liebigstrasse 20, D-04103 Leipzig, Germany. ${ }^{5}$ Department of Surgery, Surgical Intensive Care Unit, University Hospital Carl Gustav Carus, Fetscherstrasse 74, D-01307 Dresden, Germany. ${ }^{6}$ Innovation Center Computer Assisted Surgery (ICCAS), University of Leipzig, Semmelweisstrasse 14, D-04103 Leipzig, Germany. ${ }^{7}$ Cardio-Pulmonary Department, Pulmonary Division, Hospital das Clínicas, University of São Paulo Medical School, Av. Dr Arnaldo 455 (Room 2206, 2nd floor), São Paulo 01246-903, Brazil.

\section{Authors' contributions}

AWR and APR contributed equally to this work. AWR, APR, DS, MS, CJ and MBPA planned the study. AWR, APR, DS, MS, HB, and UG were responsible for the data acquisition. AWR, APR, TH, AR, MS, HB, SB and UG performed the quantitative CT analysis. AWR, PMS, HW, MGA and MBPA undertook the statistical analysis. All authors contributed to the preparation of the manuscript. The principal investigators, AWR and APR, had full access to the data analyzed in the study and take full responsibility for the integrity of all of the data and the accuracy of the data analysis.

\section{Competing interests}

The authors declare that they have no competing interests.

Received: 8 December 2010 Revised: 31 January 2011

Accepted: 25 February 2011 Published: 25 February 2011 


\section{References}

1. Bernard GR, Artigas A, Brigham KL, Carlet J, Falke K, Hudson L, Lamy M, Legall JR, Morris A, Spragg R: The American-European Consensus Conference on ARDS: definitions, mechanisms, relevant outcomes, and clinical trial coordination. Am J Respir Crit Care Med 1994, 149:818-824.

2. Spragg RG, Bernard GR, Checkley W, Curtis JR, Gajic O, Guyatt G, Hall J, Israel E, Jain M, Needham DM, Randolph AG, Rubenfeld GD, Schoenfeld D, Thompson BT, Ware LB, Young D, Harabin AL: Beyond mortality: future clinical research in acute lung injury. Am J Respir Crit Care Med 2010 181:1121-1127.

3. Croce MA, Fabian TC, Davis KA, Gavin TJ: Early and late acute respiratory distress syndrome. J Trauma 1999, 46:361-366.

4. Dicker RA, Morabito DJ, Pittet JF, Campbell AR, Mackersie RC: Acute respiratory distress syndrome criteria in trauma patients: why the definitions do not work. J Trauma 2004, 57:522-526.

5. Johannigman JA, Miller SL, Davis BR, Davis K Jr, Campbell RS, Branson RD: Influence of low tidal volumes on gas exchange in acute respiratory distress syndrome and the role of recruitment maneuvers. J Trauma 2003, 54:320-325.

6. Kwon A, Sorrells DL Jr, Kurkchubasche AG, Cassese JA, Tracy TF Jr, Luks Fl: Isolated computed tomography diagnosis of pulmonary contusion does not correlate with increased morbidity. J Pediatr Surg 2006, 41:78-82.

7. Schild HH, Strunk H, Weber W, Stoerkel S, Doll G, Hein K, Weitz M: Pulmonary contusion: CT vs plain radiograms. J Comput Assist Tomogr 1989, 13:417-420.

8. Levitt JE, Bedi H, Calfee CS, Gould MK, Matthay MA: Identification of early acute lung injury at initial evaluation in an acute care setting prior to the onset of respiratory failure. Chest 2009, 135:936-943.

9. Gattinoni L, Caironi P, Pelosi P, Goodman LR: What has computed tomography taught us about the Acute Respiratory Distress Syndrome? Am J Respir Crit Care Med 2001, 164:1701-1711.

10. Gattinoni L, Caironi P, Cressoni M, Chiumello D, Ranieri VM, Quintel M, Russo S, Patroniti N, Cornejo R, Bugedo G: Lung recruitment in patients with the acute respiratory distress syndrome. N Engl J Med 2006 , 354:1775-1786

11. Puybasset L, Cluzel P, Gusman P, Grenier P, Preteux F, Rouby JJ: Regional distribution of gas and tissue in acute respiratory distress syndrome. I. Consequences for lung morphology. CT Scan ARDS Study Group. Intensive Care Med 2000, 26:857-869.

12. Patroniti N, Bellani G, Maggioni E, Manfio A, Marcora B, Pesenti A: Measurement of pulmonary edema in patients with acute respiratory distress syndrome. Crit Care Med 2005, 33:2547-2554.

13. Rouby JJ, Puybasset L, Nieszkowska A, Lu Q: Acute respiratory distress syndrome: lessons from computed tomography of the whole lung. Crit Care Med 2003, 31(Suppl 4):S285-S295.

14. Gattinoni L, Cressoni M: Quantitative CT in ARDS: towards a clinical tool? Intensive Care Med 2010, 36:1803-1804.

15. Brismar B, Hedenstierna G, Lundquist H, Strandberg A, Svensson L, Tokics L: Pulmonary densities during anesthesia with muscular relaxation: a proposal of atelectasis. Anesthesiology 1985, 62:422-428.

16. Groeneveld AB: Increased permeability-oedema and atelectasis in pulmonary dysfunction after trauma and surgery: a prospective cohort study. BMC Anesthesiol 2007, 7:7.

17. Gajic O, Frutos-Vivar F, Esteban A, Hubmayr RD, Anzueto A: Ventilator settings as a risk factor for acute respiratory distress syndrome in mechanically ventilated patients. Intensive Care Med 2005, 31:922-926.

18. dos Santos CC, Slutsky AS: Protective ventilation of patients with acute respiratory distress syndrome. Crit Care 2004, 8:145-147.

19. Tsukamoto T, Chanthaphavong RS, Pape HC: Current theories on the pathophysiology of multiple organ failure after trauma. Injury 2010, 41:21-26.

20. O'Toole RV, O'Brien M, Scalea TM, Habashi N, Pollak AN, Turen $\mathrm{CH}_{\text {: }}$ Resuscitation before stabilization of femoral fractures limits acute respiratory distress syndrome in patients with multiple traumatic injuries despite low use of damage control orthopedics. J Trauma 2009, 67:1013-1021.

21. Schreiter D, Reske A, Stichert B, Seiwerts M, Bohm SH, Kloeppel R, Josten C: Alveolar recruitment in combination with sufficient positive endexpiratory pressure increases oxygenation and lung aeration in patients with severe chest trauma. Crit Care Med 2004, 32:968-975.
22. Reske A, Seiwerts M, Reske A, Gottschaldt U, Schreiter D: Early recovery from post-traumatic acute respiratory distress syndrome. Clin Physiol Funct Imaging 2006, 26:376-379.

23. Duggan M, Kavanagh BP: Pulmonary atelectasis: a pathogenic perioperative entity. Anesthesiology 2005, 102:838-854.

24. Vallier HA, Cureton BA, Ekstein C, Oldenburg FP, Wilber JH: Early definitive stabilization of unstable pelvis and acetabulum fractures reduces morbidity. J Trauma 2010, 69:677-684

25. Reske AW, Reske AP, Gast HA, Seiwerts M, Beda A, Gottschaldt U, Josten C Schreiter D, Heller N, Wrigge H, Amato MB: Extrapolation from ten sections can make CT-based quantification of lung aeration more practicable. Intensive Care Med 2010, 36:1836-1844

26. Schoenfeld DA, Bernard GR, ARDS Network: Statistical evaluation of ventilator-free days as an efficacy measure in clinical trials of treatments for acute respiratory distress syndrome. Crit Care Med 2002, 30:1772-1777.

27. Murray JF, Matthay MA, Luce JM, Flick MR: An expanded definition of the adult respiratory distress syndrome. Am Rev Respir Dis 1988, 138:720-723.

28. Civil ID, Schwab CW: The Abbreviated Injury Scale, 1985 revision: a condensed chart for clinical use. J Trauma 1988, 28:87-90

29. Pape HC, Remmers D, Rice J, Ebisch M, Krettek C, Tscherne H: Appraisal of early evaluation of blunt chest trauma: development of a standardized scoring system for initial clinical decision making. J Trauma 2000, 49:496-504.

30. Reske AW, Busse $H$, Amato MB, Jaekel M, Kahn T, Schwarzkopf $P$, Schreiter D, Gottschaldt U, Seiwerts M: Image reconstruction affects computer tomographic assessment of lung hyperinflation. Intensive Care Med 2008, 34:2044-2053.

31. Huber-Wagner S, Lefering R, Qvick LM, Körner M, Kay MV, Pfeifer KJ, Reiser M, Mutschler W, Kanz KG, Working Group on Polytrauma of the German Trauma Society: Effect of whole-body $\mathrm{CT}$ during trauma resuscitation on survival: a retrospective, multicentre study. Lancet 2009, 373:1455-1461.

32. Kim H, Maekado M, Tan JK, Ishikawa S, Tsukuda M: Automatic extraction of ground-glass opacity shadows on $\mathrm{CT}$ images of the thorax by correlation between successive slices. Proceedings of the 17th IEEE International Conference on Tools with Artificial Intelligence (ICTAI'05) 2005, 607-612.

33. Li R, Lewis JH, Cerviño LI, Jiang SB: 4D CT sorting based on patient internal anatomy. Phys Med Biol 2009, 54:4821-4833.

34. Li G, Xie H, Ning H, Lu W, Low D, Citrin D, Kaushal A, Zach L, Camphausen K, Miller RW: A novel analytical approach to the prediction of respiratory diaphragm motion based on external torso volume change. Phys Med Biol 2009, 54:4113-4130.

35. Borges JB, Okamoto VN, Matos GF, Caramez MP, Arantes PR, Barros F, Souza CE, Victorino JA, Kacmarek RM, Barbas CS, Carvalho CR, Amato MB: Reversibility of lung collapse and hypoxemia in early acute respiratory distress syndrome. Am J Respir Crit Care Med 2006, 174:268-278.

36. Clinical and Laboratory Standards Institute: Defining, establishing, and verifying reference intervals in the clinical laboratory: approved guideline. 3 edition. Wayne, PA: Clinical and Laboratory Standards Institute; 2008, CLSI Document C28-A3

37. Horn PS, Pesce AJ, Copeland BE: A robust approach to reference interval estimation and evaluation. Clin Chem 1998, 44:622-631.

38. Deeks J: Are you sure that's a standard deviation? (part 1). Cochrane News 1997, 10:11-12

39. Bland JM, Altman DG: Statistical methods for assessing agreement between two methods of clinical measurement. Lancet 1986, 1:307-310.

40. Whimster WF, Macfarlane AJ: Normal lung weights in a white population. Am Rev Respir Dis 1974, 110:478-483.

41. Baumann A, Audibert G, McDonnell J, Mertes PM: Neurogenic pulmonary edema. Acta Anaesthesiol Scand 2007, 51:447-455.

42. de Hemptinne Q, Remmelink M, Brimioulle S, Salmon I, Vincent JL: ARDS: a clinicopathological confrontation. Chest 2009, 135:944-949.

43. Gattinoni L, Pesenti A, Bombino M, Baglioni S, Rivolta M, Rossi F, Rossi G, Fumagalli R, Marcolin R, Mascheroni D, Torresin A: Relationships between lung computed tomographic density, gas exchange, and PEEP in acute respiratory failure. Anesthesiology 1988, 69:824-832.

44. Hubmayr RD: Perspective on lung injury and recruitment: a skeptical look at the opening and collapse story. Am J Respir Crit Care Med 2002, 165:1647-1653. 
45. Pelosi $\mathrm{P}$, Jaber $\mathrm{S}$ : Noninvasive respiratory support in the perioperative period. Curr Opin Anaesthesiol 2010, 23:233-238.

46. Richardson JD, Woods D, Johanson WG Jr, Trinkle JK: Lung bacterial clearance following pulmonary contusion. Surgery 1979, 86:730-735.

47. van Kaam AH, Lachmann RA, Herting E, De Jaegere A, van Iwaarden F, Noorduyn LA, Kok JH, Haitsma JJ, Lachmann B: Reducing atelectasis attenuates bacterial growth and translocation in experimental pneumonia. Am J Respir Crit Care Med 2004, 169:1046-1053.

48. Ferreyra G, Long $Y$, Ranieri VM: Respiratory complications after major surgery. Curr Opin Crit Care 2009, 15:342-348.

49. Antonelli M, Moro ML, Capelli O, De Blasi RA, D’Errico RR, Conti G, Bufi M, Gasparetto A: Risk factors for early onset pneumonia in trauma patients. Chest 1994, 105:224-228.

50. Leone M, Brégeon F, Antonini F, Chaumoître K, Charvet A, Ban LH, Jammes $Y$, Albanèse J, Martin C: Long term outcome in chest trauma. Anesthesiology 2008, 109:864-871.

51. Stewart RM, Park PK, Hunt JP, McIntyre RC Jr, McCarthy J, Zarzabal LA, Michalek JE, National Institutes of Health/National Heart, Lung, and Blood Institute Acute Respiratory Distress Syndrome Clinical Trials Network: Less is more: improved outcomes in surgical patients with conservative fluid administration and central venous catheter monitoring. J Am Coll Surg 2009, 208:725-735.

52. Miller PR, Croce MA, Bee TK, Qaisi WG, Smith CP, Collins GL, Fabian TC: ARDS after pulmonary contusion: accurate measurement of contusion volume identifies high-risk patients. J Trauma 2001, 51:223-228.

53. Miller PR, Croce MA, Kilgo PD, Scott J, Fabian TC: Acute respiratory distress syndrome in blunt trauma: identification of independent risk factors. Am Surg 2002, 68:845-850.

54. Michelet $P$, Couret $D$, Brégeon $F$, Perrin $G$, D'Journo XB, Pequignot $V$, Vig $V$, Auffray JP: Early onset pneumonia in severe chest trauma: a risk factor analysis. J Trauma 2010, 68:395-400.

55. Bouhemad B, Richecoeur J, Lu Q, Malbouisson LM, Cluzel P, Rouby JJ, ARDS CT Scan Study Group: Effects of contrast material on computed tomographic measurements of lung volumes in patients with acute lung injury. Crit Care 2003, 7:63-71.

doi: $10.1186 /$ cc10060

Cite this article as: Reske et al:: Computed tomographic assessment of lung weights in trauma patients with early posttraumatic lung dysfunction. Critical Care 2011 15:R71.

\section{Submit your next manuscript to BioMed Central and take full advantage of:}

- Convenient online submission

- Thorough peer review

- No space constraints or color figure charges

- Immediate publication on acceptance

- Inclusion in PubMed, CAS, Scopus and Google Scholar

- Research which is freely available for redistribution

Submit your manuscript at www.biomedcentral.com/submit 